\title{
Effect of methacholine induced bronchoconstriction on the spectral characteristics of breath sounds in asthma
}

\author{
D P S Spence, S Bentley, D H Evans, M D L Morgan
}

Department of Respiratory Medicine, Glenfield General Hospital, Leicester D P S Spence M D L Morgan

University

Department of

Medical Physics,

Leicester

$S$ Bentley

D H Evans

Correspondence to: Dr D P S Spence, Aintree Chest Centre, Fazakerley Hospital, Liverpool L7 7AL

Accepted 5 March 1992

\begin{tabular}{|c|c|c|c|c|c|}
\hline \multirow[b]{3}{*}{ Subject } & \multirow[b]{3}{*}{ Height (m) } & \multirow[b]{3}{*}{ Age (y) } & \multicolumn{3}{|c|}{$F E V_{1}(l)$} \\
\hline & & & \multicolumn{2}{|c|}{ Baseline } & \multirow[b]{2}{*}{ Predicted $\ddagger$} \\
\hline & & & Day 1 & Day 2 & \\
\hline $\begin{array}{l}1 \\
2 \\
3^{\star} \\
4^{\star} \\
5^{\star} \\
6 \dagger\end{array}$ & $\begin{array}{l}1.9 \\
1.8 \\
1.85 \\
1.5 \\
1.85 \\
1.6\end{array}$ & $\begin{array}{l}33 \\
28 \\
52 \\
23 \\
32 \\
24\end{array}$ & $\begin{array}{l}4 \cdot 8 \\
4 \cdot 8 \\
3 \cdot 3 \\
3 \cdot 0 \\
4 \cdot 2 \\
1 \cdot 3\end{array}$ & $\begin{array}{l}4 \cdot 65 \\
3 \cdot 8 \\
2 \cdot 95 \\
3 \cdot 1 \\
4 \cdot 25 \\
2 \cdot 5\end{array}$ & $\begin{array}{l}5 \cdot 16 \\
4 \cdot 64 \\
4 \cdot 27 \\
2 \cdot 77 \\
4 \cdot 85 \\
3 \cdot 06\end{array}$ \\
\hline
\end{tabular}

*Asthmatic subjects with noctural symptoms (the others were hospital staff with no noctural symptoms)

† Subject 6 was started on a beclomethasone dipropionate metered dose inhaler $1 \mathrm{mg}$ twice daily immediately after visit 1 -hence the widely different baseline FEV, values on the two test days.

†On the basis of Knudson et al. ${ }^{7}$

\begin{abstract}
Background Analysis of breath sounds
Abstract
Background Analysis of breath sounds by digital techniques offers an attractive non-invasive method of monitoring changes in airway calibre. Asthmatic breath sounds have been analysed and related to changes in forced expiratory volume in one second $\left(F E V_{1}\right)$.

Methods Bronchoconstriction was induced with methacholine in six asthmatic subjects on two occasions and changes in FEV $_{1}$ and breath sound spectra were measured.

Results Audible wheeze appeared after a mean (SE) fall in FEV of $35 \%(6 \cdot 3 \%)$ but the level was not reproducible within patients. The mean and median frequency of the spectra of breath sounds correlated with the percentage of predicted $\mathrm{FEV}_{1}(\mathrm{r}=-0.5$ and -0.6 respectively; $p<0.001)$. Inclusion of the quartile frequencies in a stepwise multiple regression reduced the residual variance by a further $9 \%$.

Conclusion Detecting changes in airway calibre by this method of sound analysis so far produces qualitative data only and will not yield quantitative data in individual patients.
\end{abstract}

(Thorax 1992;47:680-683)

Breath sound analysis would offer an attractive non-invasive method of monitoring changes in airway calibre if the sounds were shown to relate reproducibly to indices of airflow limitation. This tool could prove especially useful in the study of nocturnal asthma as measurements could be made without disturbing the patient.

Anderson et al have recently shown that after histamine challenge a change in median frequency (the frequency below which $50 \%$ of the power of the spectrum lies) occurs before the presence of audible wheeze and found change in FEV, to be related to sound spectra. Baughman and Louden found a relation between the duration of wheeze in a respiratory cycle and $\mathrm{FEV}_{1}$ in patients with asthma during moderate to severe attacks of airflow obstruction and used this as a means of monitoring airflow obstruction during sleep. ${ }^{2}$

We have induced changes in airway calibre by means of methacholine challenge and recorded the breath sounds to determine their relation to $F E V_{1}$. We examined the reproducibility of the relationship by repeat challenge.

\section{Methods}

Four patients with asthma were recruited from hospital outpatient clinics (all complained of noctural wheeze) and two asthmatic subjects from the staff of the hospital (no nocturnal symptoms)-see table. The subjects attended the laboratory for two visits at the same time of day one week apart. Each had baseline spirometry performed in the sitting position (best of three FEV , measurements) and then went on to receive a methacholine challenge by the method of Yan et al. ${ }^{12}$ Spirometry (best of two $F E V_{1}$ measurements) was performed one to two minutes after the administration of each doubling concentration of methacholine, and after a further 30 seconds the breath sounds were recorded for one minute. Before each recording the subject was instructed to breathe in the manner that was most comfortable for the degree of induced bronchoconstriction. The concentration of methacholine was increased until wheeze was heard. After the methacholine challenge $5 \mathrm{mg}$ nebulised salbutamol was administered, and after $10 \mathrm{~min}$ utes a further FEV 1 measurement and breath sound recording were made.

All experiments were performed in a sound proof room. Breath sounds were detected by a Knowles BL 1671 Electret Condenser microphone with a flat frequency response from 100 to $2000 \mathrm{~Hz}$ set in a plastic housing, fixed over the trachea at the suprasternal notch by an adhesive pad. The signal was transmitted by a 
Figure 1 Change in median frequency with falling FEV, expressed as $\%$ predicted for all six subjects.

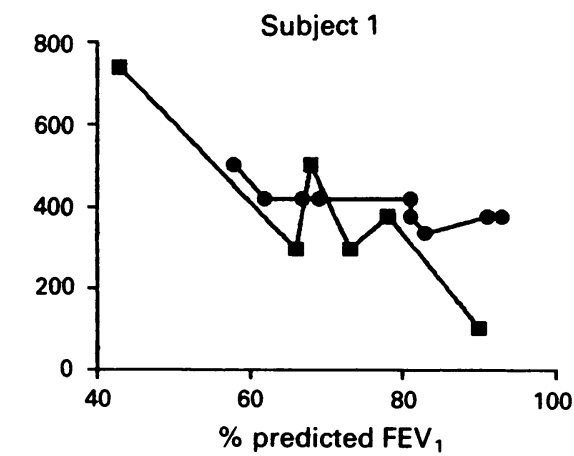

Subject 3
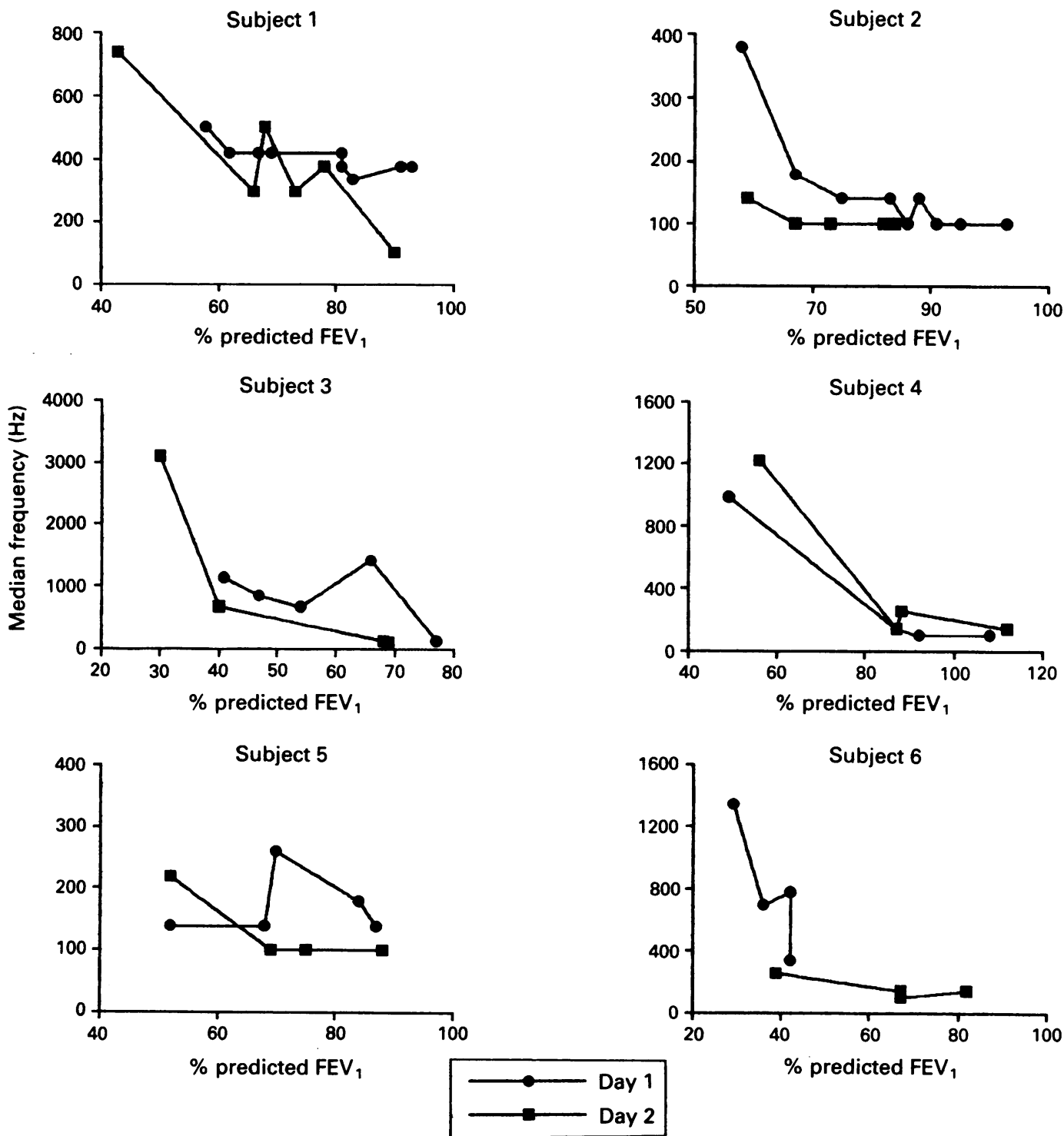

radio transmitter (TOA WM-330) and received by a radio receiver (TOA WT-730) situated outside the sound proof room to minimise sound interference from the processing equipment and investigators. The breath sounds were recorded for offline analysis on digital audio tape (Sony 1000ES DAT). A real time sound spectrograph was displayed on a monitor with a fast Fourier transform spectrum analyser consisting of a digital signal processing board (Texas Instruments TMS 32020 chip) and a Research Machine Nimbus microcomputer. ${ }^{9}$ This analyser produces a new spectrum every $12.5 \mathrm{~ms}$ from the previous $25 \mathrm{~ms}$ of audio data, giving a spectral resolution of about $40 \mathrm{~Hz}$.

Each tape was subsequently replayed into the spectrum analyser that was used during the acquisition phase. The spectral information was obtained from a 12 second sample of sound chosen from the one minute recording (determined by auscultation by a trained nonmedical observer). This material was free from movement artefact and if audible wheeze was present during any of the recording this was used. These power spectra were then averaged to produce a mean spectrum, from which were calculated the mean frequency, the median frequency, and the frequency below which $25 \%$ and $75 \%$ of the power of the sample lay.

Statistical analysis was by means of paired $t$ tests, Wilcoxon signed rank tests and stepwise multiple regression as appropriate. For all analyses the Microstat package was used.

The study was approved by the local ethical committee.

\section{Results}

Wheeze was not heard until $\mathrm{FEV}_{1}$ had fallen by a mean (SE) of $35 \%(6.3 \%)$. It was not evident in two challenges (subject 4 on day 1 and subject 6 on day 2) even though the $\mathrm{FEV}_{1}$ fell by $55 \%$ and $61 \%$ from baseline. The level of $\mathrm{FEV}_{1}$ at which audible wheeze appeared was not reproducible, differing widely both between patients and also within patients on different test days. In subject 4 , for example, wheeze appeared at an FEV of 2.451 on day 2 , but was not heard on day 1 even though the $F E V_{1}$ fell to 1.351 .

In all recordings a rise in the mean frequency of the averaged spectrum occurred as bronchoconstriction was induced (fig 1). The baseline group mean frequency was 357 (41) 
Figure 2 Mean frequency versus fall in $F E V_{1}$ expressed as $\%$ predicted.

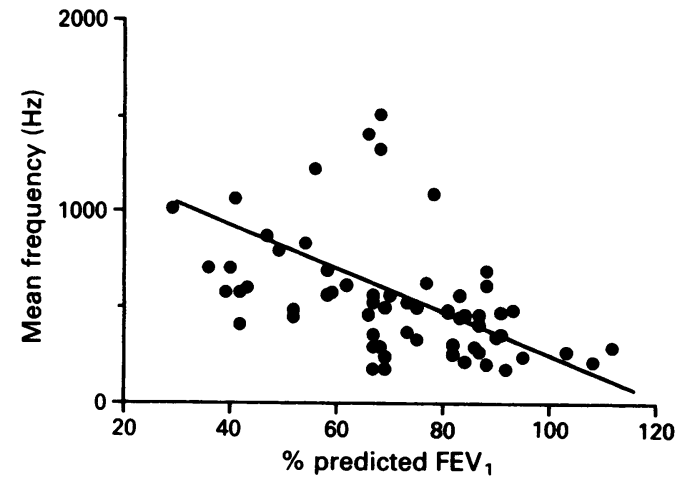

$\mathrm{Hz}$, rising to 925 (201) $\mathrm{Hz}$ for the recording made at the lowest $\mathrm{FEV}_{1}(\mathrm{p}<0.01)$. The rise in frequency began before and was independent of the development of audible wheeze (the group mean frequency of the spectrum at the lowest $\mathrm{FEV}_{1}$ without audible wheeze was 648 (102) $\mathrm{Hz}(\mathrm{p}<0.02)$.

Individual mean frequencies at baseline $\mathrm{FEV}_{1}$ differed between days and in some subjects these differences were independent of differences in baseline $\mathrm{FEV}_{1}$. The rise in mean frequency with increasing bronchoconstriction was not reproducible and neither were the changes in median frequency (fig 1).

When the grouped data from the two days were analysed (after normalisation between subjects by expressing $\mathrm{FEV}_{1}$ as \% predicted values) there was a significant relation between changes in \% predicted $\mathrm{FEV}_{1}$ and the rise in the mean frequency of the average spectrum $(\mathrm{r}=-0.5, \mathrm{p}<0.001)$.

More information on the frequency distribution of sonic power within the spectrum can be obtained from the median and quartile frequencies (those frequencies below which $25 \%, 50 \%$, and $75 \%$ of the power of the spectrum lie). Percentage of predicted FEV was more strongly related to median than to mean frequency $(\mathrm{r}=-0.6, \mathrm{p}<0.001)$ and inclusion of the other quartile frequencies in a stepwise multiple regression analysis reduced the residual variance of the relationship between $\%$ predicted $\mathrm{FEV}_{1}$ and the averaged sound spectra by $9 \%$. If those recordings with audible wheeze were excluded from the analysis, the relationship remained significant (mean frequency $\mathrm{r}=-0.43, \mathrm{p}<0.003$; median frequency $\mathrm{r}=-0.53, \mathrm{p}<0.001$ ).

\section{Discussion}

We have shown a relationship between $F_{1}$ and the sound spectra of breath sounds in subjects with asthma. Although two (Nos 2 and 6 ) of our subjects had different baseline FEV (4.8 and $3.81,1.3$ and 2.51 ), their data were included because we were anxious to examine whether $\mathrm{FEV}_{1}$ and lung sounds were related regardless of the method of induction of these changes. The baseline sound spectra were different even when the starting values of $\mathrm{FEV}_{1}$ were similar.

At present data on the change in the spectra of breath sounds during bronchoconstriction are limited. ${ }^{1}$ In this study we have sought to show the reproducibility of the relation of sounds to airflow obstruction and, by recording the whole respiratory cycle during tidal breathing with a microphone fixed over the suprasternal notch, have attempted to produce a practical system that allows sleeping subjects to be studied. In a previous study ${ }^{1}$ a microphone was held by hand over the chest wall, and two inspiratory breaths were recorded after each doubling dose of histamine. No mention is made of whether the breaths were tidal or whether the subjects inspired to total lung capacity. Only the first $\mathbf{0 . 8 5}$ seconds of each breath were analysed. We chose a 12 second period for practical reasons. Each 12 second sample should contain about three representative whole tidal breaths-more than were analysed by Anderson's group. Twelve seconds may be insufficient, however, to overcome between breath variability and may be responsible for some of the variability seen in our results.

We induced more severe bronchoconstriction in our subjects-up to the point where wheeze was audible. We were surprised by the large change in $\mathrm{FEV}_{1}$ before audible wheeze was detected, emphasising the need for objective measures of airflow obstruction instead of auscultation in assessing the severity of bronchoconstriction. The four subjects with noctural symptoms described their degree of bronchoconstriction when they were wheezing as subjectively similar to the bronchoconstriction they had on awakening, suggesting large increases in bronchoconstriction in this group during sleep.

The lack of relationship of fall in $\mathrm{FEV}_{1}$ to audible wheeze contrasts with the results of Baughman et al. ${ }^{2}$ They showed a relation between $\mathrm{FEV}_{1}$ and the duration of wheeze within a respiratory cycle as a proportion of the total duration of the respiratory cycle in subjects with spontaneous bronchoconstriction. Their subjects had more severe airflow obstruction than ours (mean FEV 1.05 $(0 \cdot 26)$ l) and were chosen because they had wheeze.

Our results suggest that in those with less severe asthma audible wheeze is a very unreliable indicator of induced bronchoconstriction.

The level of FEV 1 at which wheeze became audible may have been more reproducible in our study if a longer period of sound had been recorded. Baughman et al recorded 30 minutes of sound, of which a five minute sample was digitised. From this, 50 segments of $250 \mathrm{~ms}$ were analysed for the presence of wheeze. Alternatively, the proposed mechanism of production of wheeze may explain the lack of a reproducible relation between $F E V_{1}$ and audible wheezing. Forgacs ${ }^{5}$ suggested that a wheeze is produced by a mechanism similar to that producing the note from a toy trumpet. In this instrument the note depends solely on the mass and elasticity of the reed, but is unaffected by the velocity of airflow and by the density or temperature of the driving gas. The number of bronchi that fulfil the conditions for the production of wheeze need be only a very small percentage of the total number, and the wheeze from those that do may be widely transmitted. 
It is not surprising therefore that no relationship exists between $\mathrm{FEV}_{1}$, which is dependent on narrowing of many airways, and wheeze, which requires only a critical degree of narrowing in a solitary bronchus.

The lack of reproducibility of the changes in mean and median frequencies that we have shown may reflect a lack of standardisation of the volume history. Rate and depth of breathing are known to change breath sounds. ${ }^{8}$ No attempt was made to ensure breaths of similar size or similar breathing frequencies on the two test days because we wanted the method to be applicable to sleeping subjects. Our subjects were instructed to choose the pattern of breathing that was most comfortable for the degree of bronchoconstriction before each recording. Previous studies ${ }^{111}$ on the effect of induced bronchoconstriction on breathing pattern have shown conflicting results. Stewart et $a l^{10}$ found no change in breathing pattern as monitored by induction plethysmography during methacholine challenge, in contrast to other authors, ${ }^{46}$ whose subjects were studied during instrumented breathing. An alternative explanation for the lack of a reproducible relationship between the median frequency of breath sounds and the level of $\mathrm{FEV}_{1}$ (and between the presence or absence of audible wheeze and $\mathrm{FEV}_{1}$ ) may be unpredictable airway closure during expiration, ${ }^{3}$ which would influence the production of breath sound. This was the reason why Anderson et al analysed inspiratory sounds only. Other explanations may include a sampling error caused by the relative brief sample of sound analysed and differences in sound transmission on either day caused by changes in the coupling of the microphone to the skin-though every effort was made to ensure that this was similar on the two study days.

Our results suggest that the production of wheeze may be an epiphenomenon, whose mechanism of production is unrelated to that of other breath sounds. Monitoring changes in airflow obstruction by sound may be usefulfor example, in the study of nocturnal asthmabut will give only a qualitative estimation of changes in airway calibre.

We thank Mr Harry Hall for his technical assistance in data analysis.

1 Anderson K, Aitken S, Carter R, Macleod JES, Moran F. Variation of breath sound and airway calibre induced by histamine challenge. Am Rev Respir Dis 1990;141 1147-50.

2 Baughman RP, Louden RG. Lung sound analysis for continuous evaluation of airflow obstruction in asthma. Chest 1985;88:364-8.

3 Campbell EJM, Dickenson CJ, Slater JDH. Clinical physiology. Oxford: Blackwell, 1974;105-7.

4 Chadha TS, Schneider AW, Birch S, Genouri G, Sackner MA. Breathing pattern during induced bronhoconstriction. J Appl Physiol 1984;56:1053-9.

5 Forgacs P. Lung sounds. London: Baillière Tindall, 1978.

6 Kelsen SG, Prestel TF, Cherniak NS, Chester EH. Comparison of respiratory responses to external resistive parison of respiratory responses to external resistive loading

7 Knudson RJ, Slahn RC, Lebowitz MD, Burrows B. The maximal expiratory flow volume curve: normal standards -variability with age. Am Rev Respir Dis 1976;113: $587-600$.

8 Kraman SS. The relationship between airflow and lung sound amplitude in normal subjects. Chest 1984;86:225-9.

9 Schlindwein FS, Smith MJ, Evans DH. Medical and Biological Engineering and Computing 1988;26:228-32.

10 Stewart IC, Parker A, Catterall J, Douglas NJ, Flenley DC The effect of bronchial challenge on breathing patterns and arterial oxygenation in stable asthma. Chest 1989;95: $65-70$.

11 Tobin MJ, Birch S, Jenouri GA, Thackner MA. Acute effects of aerosolised metaproterenol on breathing patterns of patients with symptomatic bronchial asthma. J Allergy Clin Immunol 1985;76:166-72.

12 Yan K, Salome C, Woolcock AJ. Rapid method for measurement of bronchial responsiveness. Thorax 1983; 38:760-5. 